\title{
The chemical behaviour of food additives
}

\section{By D. J. McWeeny, Ministry of Agriculture, Fisheries and Food, Food Laboratory, Haldin House, Queen Street, Norwich}

This paper is concerned primarily with the chemistry of food additives and their reactions in food; although particular reference will be made to some reactions which involve specific nutrients most of the reactions discussed are general ones and may arise in relation to any nutrients with similar chemical features. Accordingly the paper is not concerned with specific nutritional implications of the use of additives, these being more appropriately assessed by a nutritionist than a chemist.

Whilst most food additives are essentially non-nutritive their incorporation into food can be important nutritionally. Thus the antioxidants and the preservatives are of major importance in ensuring that food remains palatable and wholesome. Without them much of our food would not retain its quality, wastage would increase and the supply of nutritious food would be substantially reduced; to that extent these food additives most certainly are not 'anti-nutritive' in the broadest sense of the term. On the other hand it is known that certain additives can transform a valuable food component into an actively harmful one e.g. the action of nitrogen trichloride ('agene') in converting methionine to methionine sulphoximine in flour (Mellanby, 1949). Alternatively they can specifically destroy certain nutritionally important substances; the classical example of this is, of course, the destruction of thiamin by sulphur dioxide. Sulphur dioxide (in various alternative forms) is widely used in foods today and has been accepted for food use for well over 2000 years. Thus the Romans and Egyptians used it for sterilizing wine vessels - producing it by burning sulphur in the way referred to by Odysseus when he commands Eurycleia, 'Bring sulphur, old dame, to cleanse from pollution, that I may purge the hall' (Homer).

Nowadays sulphur dioxide has many applications in food processing and preservation. Although defined as a preservative for legislative purposes it does have additional effects and applications e.g. as a reducing agent, an antioxidant, a retarder of both enzymic and non-enzymic browning and in the treatment of flour for biscuit making. This spectrum of applications implies a versatility in chemical behaviour which surpasses that of most other additives. Many additives are in fact quite reactive and indeed in so far as the antioxidants and preservatives are concerned some degree of chemical action is almost obligatory if the additive is to be successful. Amongst the preservatives the nitrites are another example of chemically reactive additives-used primarily in cured meats, their actions encompass effects on colour and flavour as well as an important anti-microbial effect in the control of Clostridium botulinum. Here again the variety of the effects

$0029-665^{1 / 79} / 3^{81} 3^{-2104}$ So1.00 (c) 1979 The Nutrition Society. 
achieved by the additive gives an indication of the range of reactions in which it can participate with food components.

The additives referred to above are added in quite small amounts-typically in the range of $50-2500 \mathrm{mg} / \mathrm{kg}$ and it might be expected that any chemical effects of interest to the nutritionist would be noticeable only in relation to nutrients of similarly low abundance. Generally, this may be true but it is not necessarily always the case and examples to the contrary are known. Some of the studies which have been conducted on sulphites and nitrites in recent years can be used in illustration of the concepts mentioned above.

\section{The sulphites and sulphur dioxide}

The use of sulphur dioxide and the salts of sulphurous acid in many commodities (e.g. processed fruit, vegetable, meat and cereal products) is accompanied by a significant loss in the amount of measurable $\mathrm{SO}_{2}$. The mechanisms involved in this loss and the magnitude of the observed effects are worth considering, and can be summarized as follows:

(a) Physical loss of $\mathrm{SO}_{2}$ is only possible in commodities with $\mathrm{pH}<4.0$ since above that $\mathrm{pH}$ it is present entirely as non-volatile ionic and covalent species.

(b) Loss of chemically measurable $\mathrm{SO}_{2}$ can be substantial e.g. 200-300 mg $\mathrm{SO}_{2} / \mathrm{kg}$ in dehydrated potato (Hearne \& Tapsfield, 1956) and much higher in commodities in which higher $\mathrm{SO}_{2}$ levels are permitted.

(c) Loss by oxidation to sulphate is not substantial e.g. $15-20 \%$ of the loss of $\mathrm{SO}_{2}$ in dehydrated vegetables (Mangan \& Doak, 1949; Gilbert \& McWeeny, 1976); the bulk of the loss is not due to oxidative reactions (Mangan \& Doak, 1949).

(d) Formation of a sulphonic acid of unidentified structure has been reported (Stadtman et al. 1946).

(e) Sulphonated dicarbonyls and sulphonated carbonyls are reported as the products of inhibition of non-enzymic browning by $\mathrm{SO}_{2}$ (Ingles, 1962; Burton et al. 1962).

(f) Concentrations of the sulphonated dicarbonyls derived in this way from reducing sugars and ascorbic acid in a few foods have been reported and are shown in Table I (Wedzicka \& McWeeny, I975).

Table 1. Concentration of 3-deoxy-4-sulpho osuloses in certain commodities

$\begin{array}{lcc}\text { Commodity } & \begin{array}{c}\text { Sulphonates } \\ \text { present } \\ (\mathrm{mg} / \mathrm{kg})\end{array} & \begin{array}{c}\text { Measurable } \\ \mathrm{SO}_{2} \\ (\mathrm{mg} / \mathrm{kg})\end{array} \\ \text { Cabbage, dehydrated 5-year-old } & 2509 & 537 \\ \text { Swede (before drying) } & 0 & 1914 ; 2114 \\ \text { Swede (dehydrated) } & 80 ; 84 & 1148 ; 1120 \\ \text { Swede (rehydrated cooked) } & 222 ; 144 & 0 ; 0 \\ \text { White wine } & 0 & 300 \\ \text { Lemon juice } & 5 & 280\end{array}$

-Calculated as 3-deoxy-4-sulpho pentosulose. 
(g) A considerable amount of the sulphur dioxide added to food is as yet chemically unidentified and unaccounted for. In some dehydrated vegetables the organic compounds derived from sulphite during dehydration may account for half the total sulphite incorporated into the food (Gilbert \& McWeeny, 1976).

These studies relate mostly to the reactions of the bisulphite ion in foods; other possible reactions include those of the sulphite ion. These may be exemplified by the work with $\mathrm{SO}_{2}$ in which the products derived from $\mathrm{SO}_{2}$ treatment of flour for biscuit making were studied (Thewlis \& Wade, 1974). These produced good circumstantial evidence that $\mathrm{SO}_{2}$ reacts with the disulphide bridge between cysteine residues in protein chains; one of the products is a cysteine residue, the other is thought to be an S-sulpho cysteine residue. These reactions and their products are of course very different from those involving mainly carbohydrate precursors discussed earlier and emphasize the versatile chemical nature of this additive.

Food component

Thiamin

Protein

Ascorbic acid

Reducing sugars/ amino acids

Table 2. Some effects of $\mathrm{SO}_{2}$ in foods

Effect

Cleavage of molecule

Protection of lysine residues from browning reactions

Cleavage of disulphide bonds

Reduction in rate of non-enzymic
browning

Reduction in rate of browning
Consequence

Loss of vitamin activity

Retention of essential amino acid. Retention of protein solubility

Production of cysteine S-sulphonate residues

Partial conversion to sulphonate derivative. Overall improvement in ascorbic acid retention

Formation of unacceptable colours/ odours delayed

\section{Reactions of nitrites in food}

To complement the description of the properties of sulphites given above, reference to another preservative may illustrate some additional points. The nitrites of sodium and potassium are used in cured meats for the purposes mentioned earlier; over the past few years there has been considerable interest in the possible formation of $\mathrm{N}$-nitroso compounds (particularly $\mathrm{N}$-nitrosamines) from nitrite in foods. As a class the N-nitrosamines include some of the most potent carcinogenic compounds known to man and considerable effort has been expended in attempting to establish whether they occur in food in significant amounts, and to devising methods of curing meats which retain the microbiological stability of the products but reduce the level of nitrosamine in the foods as eaten.

Nitrites (and nitrates) are components of the brines used traditionally in the curing of products like bacon and ham. Not all the changes which take place during curing are scientifically well understood but it is clear that much of the nitrite ceases to be measurable chemically and not all the products have been identified. Whilst there is much to be said for trying to identify the products and attempting to produce a 'balance sheet' showing the nitrite consumed and the products formed, the limited usefulness of this approach must be appreciated. Supposing the levels of nitrosamines found in cooked bacon are around $10 \mu \mathrm{g} / \mathrm{kg}$ as compared 
with the $100 \mathrm{mg} / \mathrm{kg}$ nitrite which are permitted; in this sort of situation even a 99.9\% successful 'balance' on nitrite reaction products could completely overlook any possible nitrosamine hazard if it were not already suspected. Over the last few years the MAFF Food Laboratories have been examining some of the other potential reactions of nitrites in foods and some of the work is summarized below.

The work has concentrated on the formation and properties of C- and S- nitroso compounds and the ways in which they may influence $\mathrm{N}$-nitrosamine formation. It has been established that:

(a) Reactions with phenolic compounds (e.g. 'smolse' phenols) can lead to the formation of nitroso-phenols. These are reactive compounds which can oxidize to the corresponding nitro-phenols (Knowles et al. 1975).

(b) Neither the nitroso- nor the nitro-phenols are nitrosating agents capable of producing $\mathrm{N}$-nitrosamines.

(c) However, the nitroso-phenols can act as catalysts in promoting $\mathrm{N}$ nitrosamine formation from the reaction between nitrite and secondary amines under moderately acid conditions (Davies \& McWeeny 1977).

(d) Reaction of nitrite with thiols can lead to formation of S-nitroso compounds under mildly acid conditions (R. Davies \& D. J. McWeeny, unpublished results).

(e) S-nitroso compounds can react with secondary amines to form nitrosamines under mildly acid conditions and at alkaline $\mathrm{pH}$.

(f) Nitrogen oxides are important intermediates in some nitrosations and are quite soluble in a lipid phase; the presence of fat or a hydrocarbon phase can cause a marked increase in the formation of nitrosamines from any amines which partition into the lipid phase to a significant extent (R. C. Massey \& D. J. McWeeny, unpublished results).

Taken as a whole these findings provide a basis from which one can attempt to understand some of the confused and apparently conflicting results which are found in the literature relating to nitrosamine formation.

In considering the relationship between the chemical behaviour of food additives and the development of anti-nutritive substances, a consideration of the processes just referred to can illustrate some of the effects which have to be taken into account. First, there is the clear illustration that $\mathrm{pH}$ can play a major part in determining which of a number of possible chemical mechanisms will dominate a particular situation. Second, they illustrate the potential importance of physical factors - in this case solubility and partition coefficients - in determining the rate of chemical reaction. Third, the work exemplifies the potentially important role which a catalytic effect can have-a minor component having an importance much greater than its low abundance would normally imply.

Taken in combination with the existing information about the chemical reactions of nitrites these findings allow some of the possible reactions of nitrite with nutrients in foods to be summarized as shown in Table 3 .

Potentially these reactions might have implications in relation to a number of vitamins (e.g. at the secondary aromatic amine and the pteroyl amine substituent in folic acid; nitrosation 'para' to the hydroxyl group on the pyridoxine ring) and 
Table 3. Some potential reactions of nitrites in foods

Food component

Lysine

Secondary amines

Phenols

Thiols

Haem pigments
Effect

Deamination

$\mathrm{N}$-nitrosation

C-nitrosation

S-nitrosation

Chelation with metals
Consequence

Loss of essential amino acid

Nitrosamine formation

Nitro and nitroso-phenols formation

Nitrosation reactions

Stable red colour formation

these possibilities illustrate the way in which a knowledge of the chemical reactivity of a food additive can be applied by the nutritionist in considering its possible effects on individual nutrients in the foods in which it is used (the same approach can also be used for contaminants).

Considerations of this kind are relatively easy to apply in relation to antinutritive effects operating through the destruction of specific nutrients whose chemical identity is well established e.g. it is not difficult to predict that nitrite will react readily with ascorbic acid. By contrast the enormous variety of chemical species in a food make it much more difficult to exclude the possibility of a harmful substance being formed. Nevertheless the experience with 'agene' and with nitrite emphasizes the need to continue to be aware of the potential problems which have to be considered when a new additive is proposed or an existing additive is employed in a new product or under new processing conditions.

\section{Conclusion}

In general food additives per se are neither nutritive nor anti-nutritive but in the case of those which are chemically reactive they can have effects which either reduce the abundance of a nutrient or promote its retention by removing an agent which normally destroys it. The reactions of additives discussed in this paper do not all directly involve nutrients but exemplify the types of chemical reactions in which these additives can participate. They illustrate the reactions which may have to be borne in mind when considering the possibility of nutrient losses or the enhancement of nutrient retention.

\section{REFERENCES}

Burton, H. S., McWeeny, D. J. \& Biltcliffe, D. O. (1962). F. Sci. Fd agric. 12, 911 .

Davies, R. \& McWeeny, D. J. (1977). Nature, Lond. 266, 657.

Davies, R., Massey, R. C. \& McWeeny, D. J. (1978). F. Sci. Fd agric. $29,62$.

Gilbert, J. \& McWeeny, D. J. (1976). F. Sci. Fd agric. $27,1145$.

Hearne, J. F. \& Tapsfield, D. (1956). F. Sci. Fd agric. 7, 210.

Homer, The Odyssey, Book XXII Translated by A. T. Murray. London: W. Heinemann.

Ingles, D. L. ( 1962). Aust. F. Chem. 15, 342.

Knowles, M. E., Gilbert, J. \& McWeeny, D. J. (1975). Y. Sci. Fd agric. 26, 267.

Mangan, J. L. \& Doak, B. W. (1949). N.Z. Fl Sci. Technol. 30B, 232.

Mellanby, E. (1949). Br. Med. F. II, 885 .

Stadtman, E. R., Hass, V. A., Mackinney, G. \& Tenner, O. (1946). Unpublished results discussed in Stadtman, E. R. (1948). Adv. Fd Res. I, 364.

Thewlis, B. H. \& Wade, P. (1974). F. Sci. Fd agric. $25,99$.

Wedzicka, B. L. \& McWeeny, D. J. (1975). Y. Sci. Fd agric. 26, 327.

\section{Printed in Great Britain}

